\title{
Comparison of the Efficacy and Safety of Rosuvastatin/Ezetimibe Combination Therapy and Rosuvastatin Monotherapy on Lipoprotein in Patients With Type 2 Diabetes: Multicenter Randomized Controlled Study
}

\author{
Jiwoo Lee - You-Cheol Hwang • Woo Je Lee · Jong Chul Won • \\ Kee-Ho Song · Cheol-Young Park · Kyu Jeung Ahn · Joong-Yeol Park
}

Received: December 12, 2019 / Published online: February 17, 2020

(C) The Author(s) 2020

\begin{abstract}
Introduction: Ezetimibe/statin combination therapy has been reported to provide additional cardioprotective effects compared to statin monotherapy. The apolipoprotein B/A1 (apoB/ A1) ratio is an effective predictor of cardiovascular diseases. The aim of this study was to compare the efficacy and safety of rosuvastatin/ezetimibe
\end{abstract}

Enhanced Digital Features To view enhanced digital features for this article go to https://doi.org/10.6084/ m9.figshare.11743578.

Electronic Supplementary Material The online version of this article (https://doi.org/10.1007/s13300020-00778-1) contains supplementary material, which is available to authorized users.

J. Lee · W. J. Lee · J.-Y. Park $(\bowtie)$

Department of Internal Medicine, Asan Medical Center, University of Ulsan College of Medicine, 88, Olympic-ro 43-gil, Songpa-gu, Seoul 05505, Korea e-mail: jypark@amc.seoul.kr

Y.-C. Hwang · K. J. Ahn ( $₫)$

Division of Endocrinology and Metabolism, Department of Medicine, Kyung Hee University Hospital at Gangdong, Kyung Hee University School of Medicine, 892, Dongnam-ro, Gangdong-gu, Seoul 05278, Korea

e-mail: ahnkj@khu.ac.kr

J. C. Won

Department of Internal Medicine, Sanggye Paik

Hospital, Inje University College of Medicine, 1342,

Dongil-ro, Nowon-gu, Seoul 01757, Korea combination therapy versus rosuvastatin monotherapy using the apoB/A1 ratio in patients with diabetes and hypercholesterolemia.

Methods: In this randomized, multicenter, open-label, parallel-group study, patients were randomly assigned to receive the combination therapy of rosuvastatin $5 \mathrm{mg}$ /ezetimibe $10 \mathrm{mg}$ once daily $(n=68)$ or monotherapy with rosuvastatin $10 \mathrm{mg}$ once daily $(n=68)$, for 8 weeks. Results: After the 8-week treatment, percentage change (least-square means \pm standard error) in the apoB/A1 ratio in the rosuvastatin/ezetimibe group was significantly decreased compared to the rosuvastatin group $(-46.14 \pm 1.58 \%$ vs. $-41.30 \pm 1.58 \%$, respectively; $P=0.03$ ). In addition, the proportion of patients achieving $>50 \%$ reduction in low-density lipoprotein-

\section{K.-H. Song}

Division of Endocrinology and Metabolism, Konkuk

University Medical Center, Konkuk University

School of Medicine, 120, Neungdong-ro,

Gwangjin-gu, Seoul 05029, Korea

\section{C.-Y. Park}

Division of Endocrinology and Metabolism, Department of Internal Medicine, Kangbuk Samsung Hospital, Sungkyunkwan University School of Medicine, 29, Saemunan-ro, Jongno-gu, Seoul 03181, Korea

e-mail: jypark@amc.seoul.kr 
cholesterol (LDL-C) and in the comprehensive lipid target (LDL-C $<70 \mathrm{mg} / \mathrm{dL}$, non-HDL-cholesterol [non-HDL-C] $<100 \mathrm{mg} / \mathrm{dL}$, and apoB $<80 \mathrm{mg} / \mathrm{dL}$ ) was significantly different between the two groups (76.5 and 73.5\% in the rosuvastatin/ezetimibe group and 47.1 and $45.6 \%$ in the rosuvastatin group, respectively; $P<0.001)$. The reduction in total cholesterol, non-HDL-C, LDL-C, and apoB were greater in the rosuvastatin/ezetimibe group than in the rosuvastatin group. Both treatments were well tolerated, and no between-group differences in drug-related adverse events were observed.

Conclusion: The apoB/A1 ratio was significantly reduced in patients receiving combination therapy with ezetimibe and rosuvastatin compared to those receiving rosuvastatin monotherapy. Both treatments were well tolerated in patients with type 2 diabetes and hypercholesterolemia.

Trial Registration: NCT03446261.

Keywords: Apolipoprotein A1; Apolipoprotein B; Ezetimibe; Rosuvastatin

\section{Key Summary Points}

Why carry out this study?

Statin-ezetimibe combination therapy has been reported to provide additional cardioprotective effects compared to statin monotherapy.

The apolipoprotein B (apoB)/ apolipoprotein A1 (apoA1) ratio is considered to be a predictor of future cardiovascular disease; however, to date few studies have compared the change in the apoB/A1 ratio in patients on statin-ezetimibe combination therapy versus those on statin therapy.

The aim of our study was to compare the efficacy and safety of the combination rosuvastatin $5 \mathrm{mg}$ /ezetimibe $10 \mathrm{mg}$ with rosuvastatin $10 \mathrm{mg}$ monotherapy, including the apoB/A1 ratio, in patients with type 2 diabetes (T2DM).

\section{What was learned from the study?}

In persons with T2DM, the addition of ezetimibe to rosuvastatin monotherapy resulted in significant reductions in the apoB/A1 ratio, a predictor of incident cardiovascular disease, and also in the lipid parameters, compared to rosuvastatin monotherapy.

Both rosuvastatin/ezetimibe combination therapy and rosuvastatin monotherapy were generally well tolerated in patients with T2DM, with no significant side effects.

\section{INTRODUCTION}

The use of statins by patients with type 2 diabetes (T2DM) and hypercholesterolemia decreases low-density lipoprotein cholesterol (LDL-C) levels and the risk of cardiovascular events [1-3]. However, many patients remain above the targeted lipid range, despite the recognized efficacy of statins to reduce cholesterol levels [4]. In addition, high-intensity statin therapy has been shown to have limited efficacy to reduce LDL-C levels and is associated with safety concerns $[5,6]$. Hence, there is a growing interest in developing supplementary or additional lipid-lowering drugs.

Ezetimibe is a lipid-lowering drug that targets the Niemann-Pick C1-like 1 (NPC1L1) protein, leading to inhibited cholesterol absorption in the small intestine [7]. A previous study that investigated the efficacy and safety of ezetimibe added as adjunct to statin therapy versus statin monotherapy found that the ezetimibe/statin combination decreased LDL-C levels and improved cardiovascular outcomes relative to statin monotherapy [8].

Apolipoprotein B (apoB) is the major apoprotein in all potentially atherogenic lipoprotein particles, and its level is considered to correspond to the number of atherogenic lipoprotein particles. Apolipoprotein A1 
(apoA1), on the other hand, is a component of high-density lipoprotein cholesterol (HDL-C) only and is considered to represent the number of antiatherogenic HDL-C particles [9]. Several studies have demonstrated that apoB and apoA1 are markers of atherosclerosis, which in turn is associated with the risk of cardiovascular disease [10-13]. In addition, several large prospective clinical studies have reported that the apoB/ apoA1 (apoB/A1) ratio is superior to other lipid parameters as a predictor of cardiovascular disease $[10,12,14-16]$.

Therefore, the aim of the present study was to evaluate the efficacy and tolerability of daily rosuvastatin $5 \mathrm{mg} /$ ezetimibe $10 \mathrm{mg}$ combination therapy in comparison to daily rosuvastatin $10 \mathrm{mg}$ monotherapy in terms of the apoB/ A1 ratio and other lipid parameters, in patients with T2DM and hypercholesterolemia.

\section{METHODS}

\section{Study Participants}

Adults aged 19-70 years who had been diagnosed with T2DM (glycated hemoglobin $[\mathrm{HbA} 1 \mathrm{c}]<8.5 \%)$ and hypercholesterolemia (LDL-C $>70 \mathrm{mg} / \mathrm{dL}$ ) were eligible for inclusion in the study. Patients were excluded if they had: uncontrolled diabetes with HbA1c $\geq 8.5 \%$, fasting $\mathrm{LDL}-\mathrm{C} \leq 70 \mathrm{mg} / \mathrm{dL}$, fasting triglyceride (TG) $\geq 400 \mathrm{mg} / \mathrm{dL}$, or total cholesterol (TC) $\geq 300 \mathrm{mg} / \mathrm{dL}$; history of statin-induced myopathy or rhabdomyolysis; history of hypersensitivity to rosuvastatin or ezetimibe; estimated glomerular filtration rate $<30 \mathrm{~mL} / \mathrm{min} / 1.73$ $\mathrm{m}^{2}$; alanine aminotransferase and/or aspartate aminotransferase levels $>3$-fold the upper limit of normal, or current active liver disease; creatine kinase levels $>3$-fold the upper limit of normal. Patients were also excluded if they had received lipid-lowering agents for $>1$ week within the 4 weeks immediately preceding the screening visit or received other investigational products within 30 days immediately prior to the screening visit. In addition to the abovementioned criteria, patients were excluded if deemed by investigators to be ineligible for participation.
A total of 161 patients were initially screened, of whom 140 were included in the study and randomly assigned to one of the two treatment groups (rosuvastatin/ezetimibe combination therapy group or rosuvastatin monotherapy group) (Fig. 1). Ultimately, 131 patients completed the study (65 in the rosuvastatin/ezetimibe group, 66 in the rosuvastatin group). Four patients were excluded from the efficacy and safety analysis: two patients in the rosuvastatin/ezetimibe group did not take the study medication, and two in the rosuvastatin group were not evaluated for primary efficacy outcome.

\section{Study Design}

This study was a randomized, multicenter, open-label, parallel-group trial conducted in five centers in South Korea from 23 February 2018 to 5 March 2019 (ClinicalTrials.gov Identifier: NCT03446261). The study conformed with the Helsinki Declaration of 1964, as revised in 2013. All participants provided written informed consent, and the study protocol was approved by the Institutional Review Board of Asan Medical Center, Institutional Review Board of Kyung Hee University Hospital at Gangdong, Institutional Review Board of Sanggye Baek Medical Center, Institutional Review Board of Konkuk Universtiy Medical Center, and Institutional Review Board of Kangbuk Samsung Hospital.

Patients were randomly assigned to receive either rosuvastatin $5 \mathrm{mg}$ /ezetimibe $10 \mathrm{mg}$ combination therapy once daily or rosuvastatin $10 \mathrm{mg}$ monotherapy once daily, for 8 weeks, in addition to standard care. The duration of the study was 10 consecutive weeks, including a 2-week screening period and an 8-week activetreatment phase. Patients visited the hospital two to three times during the study period and were scheduled for follow-up visits at 8 weeks for assessment of the efficacy and safety of the therapeutic regimen.

Coexisting conditions were presented using terms from the Medical Dictionary for Regulatory Activities Terminology (MedDRA) version 22.0 (https://www.meddra.org/) based on 


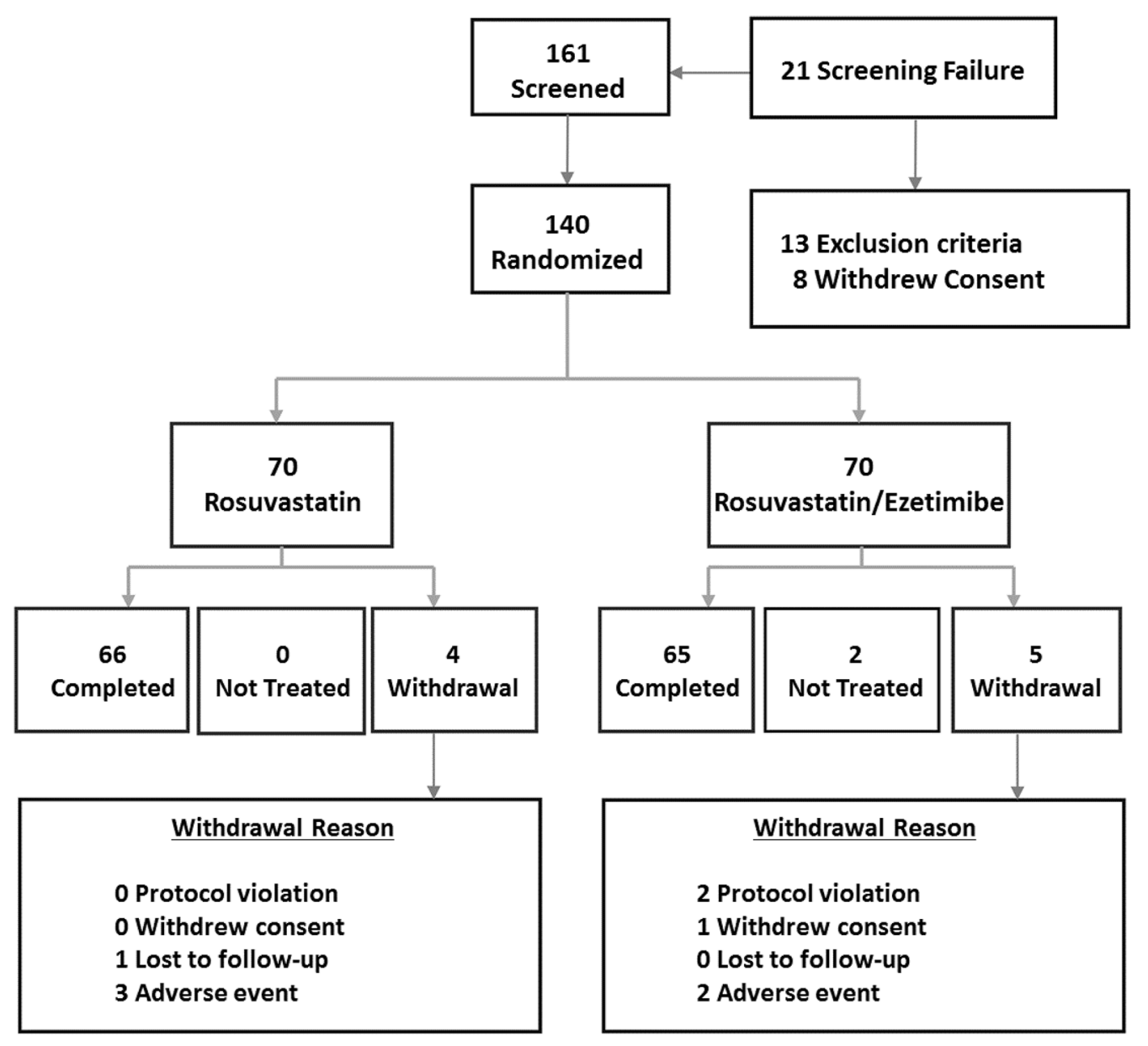

Fig. 1 Flow chart of patient distribution

patient medical records for the 3-month period immediately before the screening visit. Coronary artery disease was defined as the presence of $\geq 1$ of the following: myocardial infarction, coronary artery stenosis, unstable angina, stable angina, or ischemic cardiomyopathy. Peripheral arterial disease was defined as the presence of peripheral arterial occlusive disease or atherosclerosis of arteries.

\section{Outcomes}

The primary efficacy outcome was the percentage change in the apoB/apoA1 ratio from baseline to week 8 . The secondary efficacy outcomes at 8 weeks included the proportion patients with $>50 \%$ reduction in LDL-C; proportion of patients achieving the comprehensive lipid target (LDL-C $<70 \mathrm{mg} / \mathrm{dL}, \quad$ non-HDL$\mathrm{C}<100 \mathrm{mg} / \mathrm{dL}$, and $\mathrm{apoB}<80 \mathrm{mg} / \mathrm{dL}$ ); and changes in lipids and other parameters, including TC, non-HDL-C, LDL-C and HDL-C, TG, apoB, apoA1, apoB48, homeostatic model assessment of insulin resistance (HOMA-IR) level, high-sensitivity C-reactive protein (CRP), HbA1c, and fasting plasma glucose (FPG). Safety outcomes included adverse events (AEs), laboratory measures, and vital signs as evaluated by investigators' observations, patient-reported symptoms/signs of AEs, and results of laboratory testing.

\section{Statistical Analysis}

All analyses were performed based on the intention-to-treat population. Continuous 
Table 1 Baseline characteristics

\begin{tabular}{|c|c|c|c|}
\hline Variable & $\begin{array}{l}\text { Rosuvastatin } 10 \text { mg } \\
\text { monotherapy }(n=68)\end{array}$ & $\begin{array}{l}\text { Rosuvastatin } 5 \mathrm{mg} \text { /ezetimibe } 10 \mathrm{mg} \\
\text { combination therapy }(n=68)\end{array}$ & $P$ \\
\hline Age (year) & $56.9 \pm 8.9$ & $53.7 \pm 9.7$ & 0.05 \\
\hline Male & $38(55.9 \%)$ & $37(54.4 \%)$ & 0.86 \\
\hline Current smoking & $18(26.5 \%)$ & $14(20.6 \%)$ & 0.42 \\
\hline Alcohol drinking & $35(51.5 \%)$ & $36(52.9 \%)$ & 0.86 \\
\hline Height $(\mathrm{cm})$ & $163.2 \pm 9.7$ & $163.7 \pm 9.1$ & 0.78 \\
\hline Weight (kg) & $70.2 \pm 12.9$ & $68.2 \pm 10.9$ & 0.33 \\
\hline Body mass index $\left(\mathrm{kg} / \mathrm{m}^{2}\right)$ & $25.4 \pm 3.2$ & $26.2 \pm 3.3$ & 0.16 \\
\hline DM duration (month) & $71.2 \pm 74.4$ & $75.7 \pm 78.9$ & 0.93 \\
\hline Hypercholesterolemia duration (month) & $31.0 \pm 46.8$ & $38.3 \pm 56.8$ & 0.74 \\
\hline Systolic blood pressure (mmHg) & $125.7 \pm 14.9$ & $129.1 \pm 13.8$ & 0.06 \\
\hline Diastolic blood pressure $(\mathrm{mmHg})$ & $76.8 \pm 10.3$ & $79.0 \pm 9.1$ & 0.18 \\
\hline HbAlc $(\%)$ & $6.9 \pm 0.8$ & $7.0 \pm 0.8$ & 0.43 \\
\hline $\mathrm{FPG}(\mathrm{mg} / \mathrm{dL})$ & $127.3 \pm 29.2$ & $133.2 \pm 24.4$ & 0.05 \\
\hline Total cholesterol $(\mathrm{mg} / \mathrm{dL})$ & $205.3 \pm 30.1$ & $200.6 \pm 24.6$ & 0.52 \\
\hline Triglycerides (mg/dL) & $154.9 \pm 73.7$ & $178.9 \pm 80.2$ & 0.06 \\
\hline HDL cholesterol $(\mathrm{mg} / \mathrm{dL})$ & $51.0 \pm 12.9$ & $47.5 \pm 13.3$ & 0.07 \\
\hline LDL-cholesterol (mg/dL) & $140.0 \pm 28.1$ & $133.5 \pm 27.3$ & 0.17 \\
\hline Non-HDL cholesterol $(\mathrm{mg} / \mathrm{dL})$ & $154.3 \pm 31.0$ & $153.1 \pm 25.4$ & 0.80 \\
\hline Apolipoprotein B (mg/dL) & $119.3 \pm 22.0$ & $116.0 \pm 20.3$ & 0.36 \\
\hline Apolipoprotein A1 (mg/dL) & $139.9 \pm 25.2$ & $137.9 \pm 22.7$ & 0.46 \\
\hline Apolipoprotein $\mathrm{B} / \mathrm{A} 1$ ratio & $0.9 \pm 0.2$ & $0.9 \pm 0.2$ & 0.71 \\
\hline Apolipoprotein B48 (mg/dL) & $3940.4 \pm 3673.0$ & $4628.2 \pm 4292.8$ & 0.20 \\
\hline HOMA-IR & $2.6 \pm 2.4$ & $3.0 \pm 1.9$ & 0.17 \\
\hline High-sensitivity CRP (mg/dL) & $1.7 \pm 2.7$ & $1.3 \pm 1.4$ & 0.90 \\
\hline Coexisting conditions & & & 1.00 \\
\hline Hypertension & $17(25.0 \%)$ & $15(22.1 \%)$ & \\
\hline Coronary artery disease & $1(1.5 \%)$ & $0(0.0 \%)$ & \\
\hline Peripheral arterial disease & $4(5.9 \%)$ & $5(7.4 \%)$ & \\
\hline
\end{tabular}

Data are presented as the mean \pm standard deviation or as a number $(n)$ with the percentage in parenthesis $C R P$ C-reactive protein, $D M$ diabetes mellitus, $F P G$ fasting plasma glucose, $H D L$ high-density lipoprotein, $H O M A$ - $I R$ homeostatic model assessment for insulin resistance, $L D L$ low-density lipoprotein 
variables were expressed as the mean \pm standard deviation, and categorical variables were expressed as percentages. Student's $t$ tests were used to compare the means of continuous variables, and the $\chi^{2}$ test (Fisher's exact test) was used to compare categorical variables. For the adjusted mean difference between groups, we used the analysis of covariance model, with the results presented as least-square mean $(\mathrm{LSM}) \pm$ standard error (SE) values. The paired $t$ test was used to compare the changes in lipid and other parameters. For all analyses, a $P$ value $<0.05$ was considered to be statistically significant. All statistical analyses were performed using the SAS version 9.4 statistical package (SAS, Inc., Cary, NC, USA).

\section{RESULTS}

\section{Baseline Characteristics}

A total of 136 patients were analyzed at five medical centers, with 68 patients randomly assigned to the rosuvastatin monotherapy treatment arm of the study and 68 randomly assigned to the rosuvastatin/ezetimibe combination therapy arm. The baseline characteristics of the study patients in these two groups are given in Table 1 . The average age of the patients was 55.3 years, $55.2 \%$ were male, mean duration of diabetes was 73.4 months, and mean duration of hypercholesterolemia was 34.7 months. The baseline characteristics of the study population were balanced between groups.

\section{Efficacy}

After 8 weeks of treatment, the percentage changes in the $\mathrm{LSM} \pm$ SE from baseline in the apoB/A1 ratio were $-46.14 \pm 1.58 \%(P<0.001)$ for the rosuvastatin/ezetimibe group and $-41.30 \pm 1.58 \%(P<0.001)$ for the rosuvastatin group. Reductions in the apoB/A1 ratios in the rosuvastatin/ezetimibe group were significantly greater than those in the rosuvastatin group, with a between-group difference of $-4.93 \%$ (95\% confidence interval [CI] -9.39
Fig. 2 Efficacy of rosuvastatin monotherapy versus rosuvastatin/ezetimibe combination therapy. a Percentage change in apolipoprotein B/apolipoprotein A1 (apoB) A1) ratio from baseline to week 8 . Data in a are presented as least-square mean \pm standard error; between-group treatment difference is given under the graph with the 95\% confidence interval (CI) in parenthesis. b Proportion of patients achieving $>50 \%$ reduction in low-density lipoprotein-cholesterol $(L D L-C)$ at 8 weeks. c Proportion of patients achieving comprehensive lipid target (LDL$\mathrm{C}<70 \mathrm{mg} / \mathrm{dL}$, non-high-density lipoprotein$\mathrm{C}<100 \mathrm{mg} / \mathrm{dL}$, and $\mathrm{apoB}<80 \mathrm{mg} / \mathrm{dL}$ ) without any adverse event-related drop-out. b, c Values immediately above bars are the number of patients with the percentage in parenthesis; the difference in responder's proportion with the $95 \% \mathrm{CI}$ in parenthesis are also shown above graphs. ${ }^{* * *} P<0.001$

to $-0.47 ; P=0.03 ;$ Fig. 2 a). A significantly greater proportion of patients in the rosuvastatin/ezetimibe group (76.47\%) versus the rosuvastatin group $(47.06 \%)$ achieved $>50 \%$ reduction in LDL-C at 8 weeks. The difference between groups was $29.41 \% \quad(95 \% \quad$ CI 13.84-44.98; $P<0.001$; Fig. 2b). In addition, there were significant differences in the proportion of patients achieving the comprehensive lipid target without any AE-related dropout $(73.53 \%$ in the rosuvastatin/ezetimibe group vs. $45.59 \%$ in the rosuvastatin group), with a between-group difference of $27.94 \%$ (95\% CI 12.13-43.76; $P<0.001 ;$ Fig. 2c).

\section{Changes in Lipid Profile, Glucose Metabolism, and Inflammatory Markers}

The decreases in the LSM \pm SE of LDL-C from baseline to 8 weeks were significantly greater in the rosuvastatin/ezetimibe group than in the rosuvastatin group $(-77.3 \pm 2.6$ vs. $-63.2 \pm 2.6 \mathrm{mg} / \mathrm{dL}$, respectively; $P<0.001)$ (Table 2). In addition, after 8 weeks of treatment, TC, non-HDL-C, and apoB levels (comprehensive lipid target) were significantly reduced in the rosuvastatin/ezetimibe group relative to the rosuvastatin monotherapy group, with between-group LSM differences of $-18.8,-13.9$, and $-10.3 \mathrm{mg} / \mathrm{dL}$, respectively $(P<0.001$, respectively; Table 2$)$. On the 
a
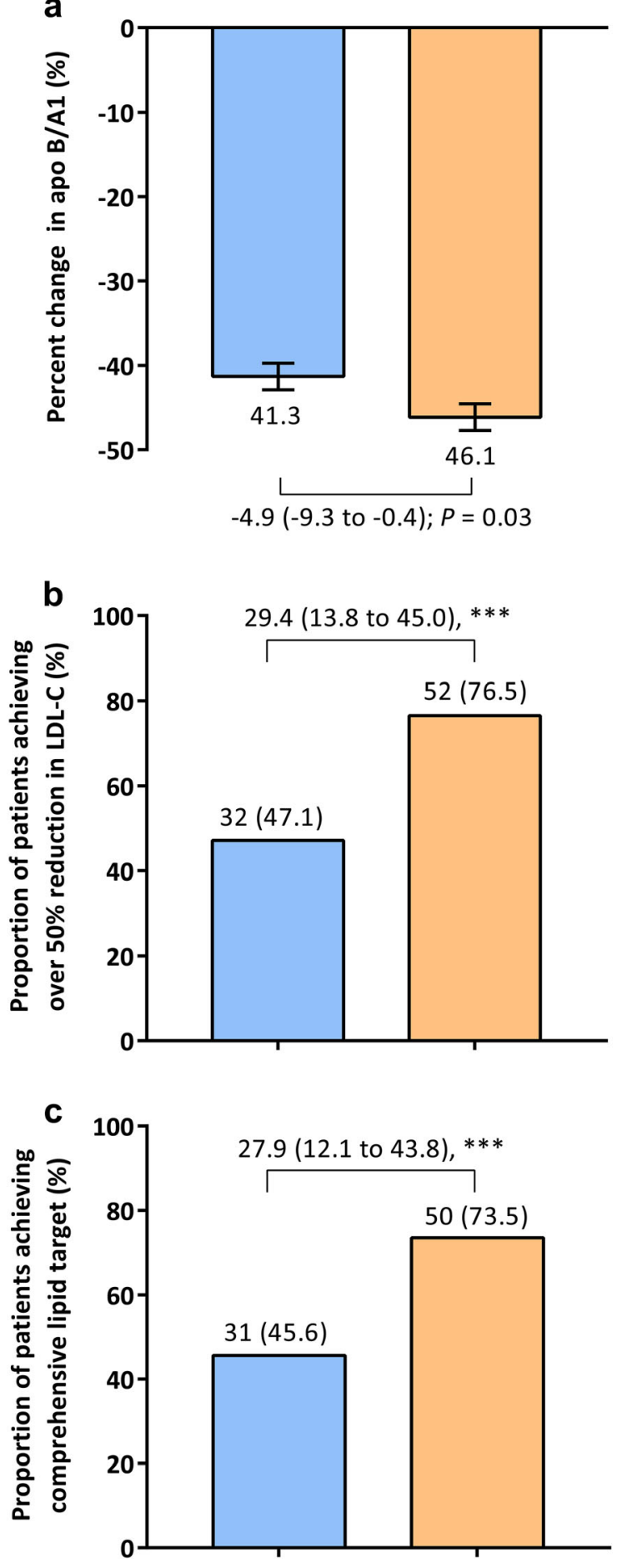

$\square$ Rosuvastatin
$\square$ Rosuvastatin/Ezetimibe

$\square$ Rosuvastatin

$\square$ Rosuvastatin/Ezetimibe

Rosuvastatin

Rosuvastatin/Ezetimibe 
Table 2 Changes in lipid parameters after 8 weeks of treatment

\begin{tabular}{lccc}
\hline Variable & $\begin{array}{l}\text { Rosuvastatin 10 mg } \\
\text { monotherapy }(\boldsymbol{n}=\mathbf{6 8})\end{array}$ & $\begin{array}{l}\text { Rosuvastatin } \mathbf{~ m g} \text { /ezetimibe } \\
\mathbf{1 0} \text { mg combination therapy } \\
(\boldsymbol{n}=\mathbf{6 8})\end{array}$ & $\boldsymbol{P}$ \\
\hline Total cholesterol (mg/dL) & $-62.6 \pm 2.8$ & $-81.4 \pm 2.8$ & $<0.001$ \\
Triglycerides (mg/dL) & $-42.8 \pm 5.9$ & $-41.6 \pm 5.9$ & 0.88 \\
HDL-cholesterol (mg/dL) & $4.5 \pm 0.8$ & $0.4 \pm 0.8$ & $<0.001$ \\
LDL-cholesterol (mg/dL) & $-63.2 \pm 2.6$ & $-77.3 \pm 2.6$ & $<0.001$ \\
Non-HDL cholesterol (mg/dL) & $-67.5 \pm 2.8$ & $-81.4 \pm 2.8$ & $<0.001$ \\
Apolipoprotein B (mg/dL) & $-43.9 \pm 2.0$ & $-54.2 \pm 2.0$ & $<0.001$ \\
Apolipoprotein A1 (mg/dL) & $9.9 \pm 1.7$ & $0.02 \pm 1.7$ & $<0.001$ \\
Apolipoprotein B48 (mg/dL) & $-149.7 \pm 375.0$ & $49.3 \pm 375.0$ & 0.79 \\
\hline
\end{tabular}

Data are presented as least-square means $(\mathrm{LSM}) \pm$ standard error (SE)

Table 3 Changes in glucose metabolism-related parameters and inflammatory marker after 8 weeks of treatment

\begin{tabular}{lccc}
\hline Variable & $\begin{array}{l}\text { Rosuvastatin } \mathbf{1 0} \mathbf{~ m g} \\
\text { monotherapy }(\boldsymbol{n}=\mathbf{6 8})\end{array}$ & $\begin{array}{l}\text { Rosuvastatin } \mathbf{5 ~} \mathbf{~ m g} / \text { ezetimibe } \\
\mathbf{1 0} \mathbf{~ m g} \text { combination therapy }(\boldsymbol{n}=\mathbf{6 8})\end{array}$ & $\boldsymbol{P}$ \\
\hline HOMA-IR & $0.44 \pm 0.26$ & $0.47 \pm 0.26$ & 0.94 \\
High-sensitivity CRP (mg/dL) & $-0.25 \pm 0.35$ & $-0.15 \pm 0.35$ & 0.84 \\
FPG (mg/dL) & $3.9 \pm 2.5$ & $6.3 \pm 2.5$ & 0.49 \\
HbAlc (\%) & $0.05 \pm 0.06$ & $0.13 \pm 0.06$ & 0.34 \\
\hline
\end{tabular}

Data are presented as $\mathrm{LSM} \pm \mathrm{SE}$

other hand, at 8 weeks, there was a significant increase in HDL-C and apoA1 levels in the rosuvastatin group $(4.5 \pm 0.8$ and $9.9 \pm 1.7 \mathrm{mg} /$ $\mathrm{dL}$, respectively) compared with the rosuvastatin/ezetimibe group $(0.4 \pm 0.8$ and $0.02 \pm 1.7 \mathrm{mg} / \mathrm{dL}$, respectively). These differences were significant at $P<0.001$ (Table 2). However, there were no significant differences in TG, HOMA-IR, high-sensitivity CRP, apoB48, FPG, and HbA1c between the two groups (Tables 2, 3).

After 8 weeks of treatment, $98.5 \%$ of patients in the rosuvastatin/ezetimibe group and $88.4 \%$ of those in the rosuvastatin group achieved the apoB/A1 ratio of $<0.7$ (Electronic Supplementary Material [ESM] Fig. 1). In addition, $77.9 \%$ of patients in the rosuvastatin/ezetimibe group and $46.4 \%$ of those in the rosuvastatin group achieved the LDL-C target $<70 \mathrm{mg} / \mathrm{dL}$ (ESM Fig. 2).

\section{Safety}

No significant differences were observed between the rosuvastatin/ezetimibe and rosuvastatin groups in terms of the percentage of patients who presented AEs (Table 4). Both treatments were generally well tolerated. Overall, the most common AEs were a mild increase in liver enzyme levels $(n=2)$ and myalgia $(n=2)$. All reports of myalgia originated in the rosuvastatin group. Serious AEs included diabetic retinopathy ( $n=1$, in the rosuvastatin/ ezetimibe group), angina pectoris ( $n=1$, in the 
Table 4 Safety assessment during the 8 weeks of the study

\begin{tabular}{lll}
\hline Variable & $\begin{array}{l}\text { Rosuvastatin monotherapy } \\
\mathbf{1 0 ~} \mathbf{~ m}(\boldsymbol{n}=\mathbf{6 8})\end{array}$ & $\begin{array}{l}\text { Rosuvastatin } \mathbf{5} \text { mg/ezetimibe } \\
\mathbf{1 0} \mathbf{~ m g} \text { monotherapy }(\boldsymbol{n}=\mathbf{6 8})\end{array}$ \\
\hline ALT or AST $\geq 3 \times \mathrm{UNL}$ & $2(2.94)$ & $2(2.94)$ \\
Myalgia & $2(2.94)$ & $0(0.00)$ \\
Abdominal distention & $0(0.00)$ & $1(1.47)$ \\
Abdominal pain & $0(0.00)$ & $1(1.47)$ \\
Urticaria & $1(1.47)$ & $0(0.00)$ \\
Peripheral edema & $0(0.00)$ & $1(1.47)$ \\
Dizziness & $0(0.00)$ & $1(1.47)$ \\
Diabetic retinopathy & $0(0.00)$ & $1(1.43)$ \\
Angina pectoris & $1(1.43)$ & $0(0.00)$ \\
Colon cancer & $1(1.43)$ & $0(0.00)$ \\
Death from any causes & $0(0.00)$ & $0(0.00)$ \\
\hline
\end{tabular}

Data are presented as the number (of patients) with the percentage in parenthesis

$A L T$ Alanine aminotransferase,\% AST Aspartate aminotransferase, UNL upper normal limit

rosuvastatin group) and colon cancer ( $n=1$, in the rosuvastatin group). However, none of these were associated with the study drug. No deaths, as a serious $\mathrm{AE}$, were noted. We recorded seven AEs resulting in permanent discontinuation of the study drugs, namely, myalgia $(n=2$, in the rosuvamibe group), abdominal distension ( $n=1$, in the rosuvastatin/ezetimibe group), abdominal pain ( $n=1$, in the rosuvastatin/ezetimibe group), peripheral edema $(n=1$, in the rosuvastatin/ezetimibe group), dizziness ( $n=1$, in the rosuvastatin/ezetimibe group), and urticaria ( $n=1$, in the rosuvamibe group).

\section{DISCUSSION}

In the present study, treatment with rosuvastatin $5 \mathrm{mg}$ /ezetimibe $10 \mathrm{mg}$ combination therapy resulted in significantly greater reductions in the apoB/A1 ratio than did rosuvastatin $10 \mathrm{mg}$ monotherapy after 8 weeks in patients with T2DM and hypercholesterolemia. In addition, the proportion of patients who achieved $>50 \%$ reduction in LDL-C and in the comprehensive lipid target was significantly greater in the rosuvastatin/ezetimibe group than in the rosuvastatin monotherapy group. Moreover, significant reductions in lipid parameters were observed in the rosuvastatin/ezetimibe group compared with the rosuvastatin group. Both therapies were generally well tolerated, and few incidents of elevated liver enzymes or myalgia were reported.

The results of previous studies on ezetimibe/ statin combination therapy demonstrate that this combination therapy has significant cholesterol-lowering $[17,18]$ and cardioprotective effects compared to statin monotherapy [8]. The side effects of statin therapy depend on the prescribed statin dose [19]. Hence, reducing the statin dosage and adding ezetimibe to the therapeutic regimen could be efficacious in the management of cholesterol and cardiovascular disease, without the statin-related AEs [20].

The ApoB/A1 ratio, as representative of the total number of atherosclerotic particles, is considered to be a stronger predictor of atherosclerosis and cardiovascular disease than LDL-C $[10,21,22]$. However, few studies have compared the use of a high-dose statin with that of the low-dose statin/ezetimibe combination, with a focus on the changes in the apoB/A1 ratio. To our knowledge, this is the first study to 
use apoB/A1 ratios to compare the efficacy of rosuvastatin $5 \mathrm{mg}$ /ezetimibe $10 \mathrm{mg}$ combination therapy and rosuvastatin $10 \mathrm{mg}$ therapy. Our results are consistent with those from a previous study that demonstrated a greater apoB/A1 lowering effect with atorvastatin $5 \mathrm{mg} /$ ezetimibe $5 \mathrm{mg}$ combination therapy than from atorvastatin $20 \mathrm{mg}$ monotherapy [23]. However, another study that compared rosuvastatin $5 \mathrm{mg}$ /ezetimibe $10 \mathrm{mg}$ combination therapy with rosuvastatin $20 \mathrm{mg}$ monotherapy reported no difference between the groups [24]. It is possible that any effects on the apoB/A1 ratio depend on the statin and/or statin or ezetimibe dose prescribed, as well as on the patient population. In our study, a significant reduction in the apoB/A1 ratio with the rosuvastatin/ezetimibe combination was observed; this reduction was due to the decrease in apoB and increase in apoA1 levels. Dual inhibition of cholesterol biosynthesis in the liver and cholesterol absorption in the intestine using a combination of ezetimibe with a statin results in further decreases in apoB [25]. In addition, the observed differences in the apoA 1 values between the two groups could be attributed to the favorable effects of rosuvastatin on apoA1, compared to other statins [26].

Previous studies have demonstrated the improved lipid-lowering effects of the ezetimibe/rosuvastatin combination compared to rosuvastatin monotherapy in patients with T2DM [24, 27]. Our study reported similar results, with a significantly higher proportion of patients in the rosuvastatin/ezetimibe group achieving $>50 \%$ reduction in LDL-cholesterol and in the comprehensive lipid target compared to the rosuvastatin monotherapy group. Patients with T2DM have an enhanced expression of the NPC1L1 gene, which promotes cholesterol absorption in the small intestine $[28,29]$. Ezetimibe binds to the NPC1L1 receptor, thereby selectively preventing cholesterol absorption from the intestine. Therefore, coadministration of ezetimibe and a statin could provide improved efficacy in patients with T2DM.

In contrast, changes in apoB48 levels showed opposite trends between the two groups, although the difference was not statistically significant. Previous studies have reported that diabetic patients have high apoB48 levels [30] and that ezetimibe might decrease apoB48 levels by inhibiting intestinal cholesterol absorption, but the differences reported were not statistically significant in these studies $[30,31]$. In present study, we also could not determine the efficacy of ezetimibe for apoB48 reduction due to the short duration of the follow-up and small sample size. Therefore, future studies are needed to clarify the effect of ezetimibe on apoB48 reduction in diabetes patients.

Several studies have reported an effect of statins on glucose metabolism [23, 31-34] and on the risk of new-onset diabetes $[35,36]$, but the results remain controversial. Results from earlier studies also suggest that ezetimibe could improve insulin resistance [37-39]. Two studies reported that the addition of ezetimibe to a statin as combination therapy improved insulin resistance and did not increase the risk of diabetes [40, 41]. However, in our study, FPG, HbA1c, and HOMA-IR did not differ between the two groups following the 8-week treatment. Previous reports evaluating the effect of the rosuvastatin/ezetimibe combination on glucose control and insulin resistance are very limited. The exact rationale underlying the reported effects of combination therapy on glucose metabolism remains unknown. Hence, further studies using large samples and longer therapeutic periods may clarify the effect of rosuvastatin and rosuvastatin/ezetimibe combination therapy on glucose metabolism.

In this study, the safety profiles observed were generally tolerable between the two groups. No drug-related serious AEs were reported, and overall the incidence of liver, muscle, gastrointestinal, and allergic AEs was low and comparable between the two treatment groups.

This study has several limitations. First, the duration of this study was relatively short and the patient population was small. Therefore, the results may not adequately represent the longterm efficacy and safety issues related to these drugs. Second, the open-label design might result in bias in the comparison of lipid profiles and affect the assessment of AEs. Third, we did 
not evaluate the effects of other doses of rosuvastatin or other statins in combination with ezetimibe. Finally, the clinical impact of apoB/ A1 changes was not reported in our study. Further studies to evaluate the implication of the apoB/A1 ratio on clinical outcomes in larger patient populations are needed.

\section{CONCLUSION}

An 8-week combination therapy of rosuvastatin $5 \mathrm{mg} /$ ezetimibe $10 \mathrm{mg}$ showed a significant reduction in the apoB/A1 ratio, a predictor of future cardiovascular disease, compared to rosuvastatin $10 \mathrm{mg}$ monotherapy, in patients with diabetes and hypercholesterolemia. No unexpected safety issues were identified, and both treatments were well tolerated.

\section{ACKNOWLEDGEMENTS}

The authors thank the contributions of study investigators and the Yuhan Corporation.

Funding. This study and the Rapid Service Fee were funded by the Yuhan Corporation, Seoul, Korea.

Authorship. All named authors meet the International Committee of Medical Journal Editors (ICMJE) criteria for authorship for this manuscript, take responsibility for the integrity of the work as a whole, and have given final approval to the version to be published.

Authorship Contributions. YCH, WJL, JCW, KHL, CYP, KJA, and JYP contributed to the conception and design of the study. All authors contributed to the analysis or interpretation of data. JL wrote the initial draft of the manuscript. All authors reviewed and revised the manuscript. All authors approved the final version of the manuscript.

Disclosures. Jiwoo Lee, You-Cheol Hwang, Woo Je Lee, Jong Chul Won, Kee-Ho Song, Cheol-Young Park, Kyu Jeung Ahn, and JoongYeol Park have nothing to disclose.
Compliance with Ethics Guidelines. The study conformed with the Helsinki Declaration Of 1964, as revised in 2013. All participants provided written informed consent, and the study protocol was approved by the Institutional Review Board of Asan Medical Center, Institutional Review Board of Kyung Hee University Hospital at Gangdong, Institutional Review Board of Sanggye Baek Medical Center, Institutional Review Board of Konkuk Universtiy Medical Center, and Institutional Review Board of Kangbuk Samsung Hospital.

Data Availability. The datasets generated during and/or analyzed during the current study are available from the corresponding author on reasonable request.

Open Access. This article is licensed under a Creative Commons Attribution-NonCommercial 4.0 International License, which permits any non-commercial use, sharing, adaptation, distribution and reproduction in any medium or format, as long as you give appropriate credit to the original author(s) and the source, provide a link to the Creative Commons licence, and indicate if changes were made. The images or other third party material in this article are included in the article's Creative Commons licence, unless indicated otherwise in a credit line to the material. If material is not included in the article's Creative Commons licence and your intended use is not permitted by statutory regulation or exceeds the permitted use, you will need to obtain permission directly from the copyright holder. To view a copy of this licence, visit http://creativecommons.org/licenses/by$\mathrm{nc} / 4.0 /$.

\section{REFERENCES}

1. Stone NJ, Robinson JG, Lichtenstein AH, et al. 2013 ACC/AHA guideline on the treatment of blood cholesterol to reduce atherosclerotic cardiovascular risk in adults: a report of the American College of Cardiology/American Heart Association Task Force on Practice Guidelines. J Am Coll Cardiol. 2014;63: 2889-934. 
2. Heart Protection Study Collaborative Group. MRC/ BHF Heart Protection Study of cholesterol lowering with simvastatin in 20,536 high-risk individuals: a randomised placebo-controlled trial. Lancet. 2002;360:7-22.

3. Baigent C, Blackwell L, Emberson J, et al. Efficacy and safety of more intensive lowering of LDL cholesterol: a meta-analysis of data from 170,000 participants in 26 randomised trials. Lancet. 2010;376:1670-81.

4. Pearson TA, Laurora I, Chu H, Kafonek S. The lipid treatment assessment project (L-TAP): a multicenter survey to evaluate the percentages of dyslipidemic patients receiving lipid-lowering therapy and achieving low-density lipoprotein cholesterol goals. Arch Intern Med. 2000;160:459-67.

5. Preiss D, Seshasai SR, Welsh P, et al. Risk of incident diabetes with intensive-dose compared with moderate-dose statin therapy: a meta-analysis. JAMA. 2011;305:2556-644.

6. Thompson PD, Panza G, Zaleski A, Taylor B. Statinassociated side effects. J Am Coll Cardiol. 2016;67: 2395-410.

7. Sudhop T, Lutjohann D, Kodal A, et al. Inhibition of intestinal cholesterol absorption by ezetimibe in humans. Circulation. 2002;106:1943-8.

8. Cannon CP, Blazing MA, Giugliano RP, et al. Ezetimibe added to statin therapy after acute coronary syndromes. N Engl J Med. 2015;372:2387-97.

9. Walldius G, Jungner I. The apoB/apoA-I ratio: a strong, new risk factor for cardiovascular disease and a target for lipid-lowering therapy-a review of the evidence. J Intern Med. 2006;259:493-519.

10. Walldius G, Jungner I, Holme I, Aastveit AH, Kolar W, Steiner E. High apolipoprotein B, low apolipoprotein A-I, and improvement in the prediction of fatal myocardial infarction (AMORIS study): a prospective study. Lancet. 2001;358: 2026-33.

11. Walldius G, Jungner I. Apolipoprotein B and apolipoprotein A-I: risk indicators of coronary heart disease and targets for lipid-modifying therapy. J Intern Med. 2004;255:188-205.

12. Yusuf S, Hawken S, Ounpuu S, et al. Effect of potentially modifiable risk factors associated with myocardial infarction in 52 countries (the INTERHEART study): case-control study. Lancet. 2004;364:937-52.

13. Sacks FM, Alaupovic P, Moye LA, et al. VLDL, apolipoproteins $\mathrm{B}$, CIII, and $\mathrm{E}$, and risk of recurrent coronary events in the Cholesterol and Recurrent
Events (CARE) trial. Circulation. 2000;102: 1886-922.

14. Meisinger C, Loewel H, Mraz W, Koenig W. Prognostic value of apolipoprotein B and A-I in the prediction of myocardial infarction in middle-aged men and women: results from the MONICA/KORA Augsburg cohort study. Eur Heart J. 2005;26:271-8.

15. Dunder K, Lind L, Zethelius B, Berglund L, Lithell H. Evaluation of a scoring scheme, including proinsulin and the apolipoprotein B/apolipoprotein A1 ratio, for the risk of acute coronary events in middle-aged men: Uppsala Longitudinal Study of Adult Men (ULSAM). Am Heart J. 2004;148: 596-601.

16. van der Steeg WA, Boekholdt SM, Stein EA, et al. Role of the apolipoprotein B-apolipoprotein A-I ratio in cardiovascular risk assessment: a case-control analysis in EPIC-Norfolk. Ann Intern Med. 2007; 146:640-8.

17. Ballantyne CM, Blazing MA, King TR, Brady WE, Palmisano J. Efficacy and safety of ezetimibe coadministered with simvastatin compared with atorvastatin in adults with hypercholesterolemia. Am J Cardiol. 2004;93:1487-94.

18. Morrone D, Weintraub WS, Toth PP, et al. Lipidaltering efficacy of ezetimibe plus statin and statin monotherapy and identification of factors associated with treatment response: a pooled analysis of over 21,000 subjects from 27 clinical trials. Atherosclerosis. 2012;223:251-61.

19. Golomb BA, Evans MA. Statin adverse effects : a review of the literature and evidence for a mitochondrial mechanism. Am J Cardiovasc Drugs. 2008;8:373-418.

20. Suh S, Jung CH, Hong SJ, Kim JS, Choi SH. Statin intolerance: an overview of the current status and possible treatment options. J Lipid Atheroscler. 2018;7:77-87.

21. Sniderman AD, Furberg CD, Keech A, et al. Apolipoproteins versus lipids as indices of coronary risk and as targets for statin treatment. Lancet. 2003;361:777-80.

22. Rahmani M, Raiszadeh F, Allahverdian S, Kiaii S, Navab M, Azizi F. Coronary artery disease is associated with the ratio of apolipoprotein A-I/B and serum concentration of apolipoprotein B, but not with paraoxonase enzyme activity in Iranian subjects. Atherosclerosis. 2002;162:381-9.

23. Her AY, Kim JY, Kang SM, et al. Effects of atorvastatin $20 \mathrm{mg}$, rosuvastatin $10 \mathrm{mg}$, and atorvastatin/ ezetimibe $5 \mathrm{mg} / 5 \mathrm{mg}$ on lipoproteins and glucose 
metabolism. J Cardiovasc Pharmacol Ther. 2010;15: 167-74.

24. Hwang YC, Jun JE, Jeong IK, Ahn KJ, Chung HY. Comparison of the efficacy of rosuvastatin monotherapy $20 \mathrm{mg}$ with rosuvastatin $5 \mathrm{mg}$ and ezetimibe $10 \mathrm{mg}$ combination therapy on lipid parameters in patients with type 2 diabetes mellitus. Diabetes Metab J. 2019. https://doi.org/10. 4093/dmj.2018.0124.

25. Tremblay AJ, Lamarche B, Hogue JC, Couture P. Effects of ezetimibe and simvastatin on apolipoprotein B metabolism in males with mixed hyperlipidemia. J Lipid Res. 2009;50:1463-71.

26. Deedwania PC, Hunninghake DB, Bays HE, Jones $\mathrm{PH}$, Cain VA, Blasetto JW. Effects of rosuvastatin, atorvastatin, simvastatin, and pravastatin on atherogenic dyslipidemia in patients with characteristics of the metabolic syndrome. Am J Cardiol. 2005;95:360-6.

27. Torimoto K, Okada Y, Mori H, et al. Efficacy of combination of Ezetimibe $10 \mathrm{mg}$ and rosuvastatin $2.5 \mathrm{mg}$ versus rosuvastatin $5 \mathrm{mg}$ monotherapy for hypercholesterolemia in patients with type 2 diabetes. Lipids Health Dis. 2013;12:137.

28. Ravid Z, Bendayan M, Delvin E, et al. Modulation of intestinal cholesterol absorption by high glucose levels: impact on cholesterol transporters, regulatory enzymes, and transcription factors. Am J Physiol Gastrointest Liver Physiol. 2008;295: G873-G885885.

29. Park SW. Intestinal and hepatic Niemann-Pick C1Like 1. Diabetes Metab J. 2013;37:240-8.

30. Park CY, Park JY, Choi J, et al. Increased postprandial apolipoprotein B-48 level after a test meal in diabetic patients: a multicenter, cross-sectional study. Metabolism. 2016;65:843-51.

31. Lee JH, Kang HJ, Kim HS, Sohn DW, Oh BH, Park YB. Effects of ezetimibe/simvastatin 10/20 mg vs. atorvastatin $20 \mathrm{mg}$ on apolipoprotein B/apolipoprotein A1 in Korean patients with type 2 diabetes mellitus: results of a randomized controlled trial. Am J Cardiovasc Drugs. 2013;13: 343-51.
32. Takano T, Yamakawa T, Takahashi M, Kimura M, Okamura A. Influences of statins on glucose tolerance in patients with type 2 diabetes mellitus. J Atheroscler Thromb. 2006;13:95-100.

33. Huptas S, Geiss HC, Otto C, Parhofer KG. Effect of atorvastatin $(10 \mathrm{mg} /$ day $)$ on glucose metabolism in patients with the metabolic syndrome. Am J Cardiol. 2006;98:66-9.

34. Moutzouri E, Liberopoulos E, Mikhailidis DP, et al. Comparison of the effects of simvastatin vs. rosuvastatin vs. simvastatin/ezetimibe on parameters of insulin resistance. Int J Clin Pract. 2011;65:1141-8.

35. Dormuth CR, Filion KB, Paterson JM, et al. Higher potency statins and the risk of new diabetes: multicentre, observational study of administrative databases. BMJ. 2014;348:g3244.

36. Ridker PM, Pradhan A, MacFadyen JG, Libby P, Glynn RJ. Cardiovascular benefits and diabetes risks of statin therapy in primary prevention: an analysis from the JUPITER trial. Lancet. 2012;380:565-71.

37. Deushi M, Nomura M, Kawakami A, et al. Ezetimibe improves liver steatosis and insulin resistance in obese rat model of metabolic syndrome. FEBS Lett. 2007;581:5664-700.

38. Adachi $\mathrm{H}$, Nakano $\mathrm{H}$, Yamamoto $\mathrm{K}$, et al. Ezetimibe ameliorates atherogenic lipids profiles, insulin resistance and hepatocyte growth factor in obese patients with hypercholesterolemia. Lipids Health Dis. 2015;14:1.

39. Park H, Shima T, Yamaguchi K, et al. Efficacy of long-term ezetimibe therapy in patients with nonalcoholic fatty liver disease. J Gastroenterol. 2011;46:101-7.

40. Dagli N, Yavuzkir M, Karaca I. The effects of high dose pravastatin and low dose pravastatin and ezetimibe combination therapy on lipid, glucose metabolism and inflammation. Inflammation. 2007;30:230-5.

41. Barkas F, Elisaf M, Liberopoulos E, Klouras E, Liamis G, Rizos EC. Statin therapy with or without ezetimibe and the progression to diabetes. J Clin Lipidol. 2016;10:306-13. 